\title{
ATTITUDES TOWARD PHYSICAL EDUCATION IN PORTUGUESE SCHOOLS: MIDDLE AND HIGH SCHOOL STUDENTS
}

original paper

(c) University School of Physical Education in Wroclaw

DOI: https://doi.org/10.5114/hm.2018.77327

\author{
RICARDO FRANCO LIMA ${ }^{1}$, FILIPE MANUEL CLEMENTE ${ }^{1,2}$, RAUL FRAGUELA VALE ${ }^{3}$ \\ ${ }^{1}$ Polytechnic Institute of Viana do Castelo, School of Sports and Leisure, Melgaço, Portugal \\ ${ }^{2}$ Instituto de Telecomunicações, Delegação da Covilhã, Covilhã, Portugal \\ ${ }^{3}$ University of A Coruña, Department of Specific Teaching Training and Research and Diagnosis Methods in Education, \\ A Coruña, Spain
}

\begin{abstract}
Purpose. The purpose of the study was to analyse possible determinants of Portuguese middle and high school students' attitudes toward physical education (PE).

Methods. The total of 949 students (48.6\% male, $51.4 \%$ female) aged $13.96 \pm 1.96$ years participated in the study. Out of these, $50.9 \%$ practised sports 2 or 3 times a week. The exploratory factor analysis resulted in 4 categories that explain $51.28 \%$ of the total variance: F1 (PE curriculum), F2 (PE teaching), F3 (practice conditions in PE), and F4 (PE benefits).

Results. The t-test analysis (between-gender) revealed that males attributed significantly more meaning (a lower average corresponds to a greater value) than females to the PE curriculum ( $p=0.001 ; d=0.277)$, PE teaching $(p=0.019 ; d=0.151)$, practice conditions in PE ( $p=0.004 ; d=0.189)$, and PE benefits $(p=0.001 ; d=0.436)$. The variance between levels of practice outside school revealed higher meaning attributed by students who practiced sports in the variables of PE curriculum ( $p=0.004 ; d=0.205)$, PE teaching ( $p=0.017 ; d=0.168)$, and PE benefits $(p=0.001 ; d=0.466)$.
\end{abstract}

Conclusions. The study results suggest that males ascribe more value to the general attributes of PE and that students who participate in sports value the meaning of PE more than those who do not.

Key words: physical education, attitudes, pedagogy, students

\section{Introduction}

In accordance with the literature, it is not easy to define attitude. Attitude depends on the target/subject and measurement (implicit or explicit attitude; unconscious and conscious processes) and can vary in terms of specificity and generality [1].

Concerning physical education, attitude has been presented by the literature as a dual-component view (affect and cognition). Affect is related to fun or enjoyment, while cognition is related to the usefulness of the attitude object [2]. Attitude influences our behaviour and, in physical education classes, teachers want students to develop positive attitudes so that they have motivation in the classes and continue their physical activity throughout their lives [3]. Attitudes toward physical education have been explored as a concept related to students' perceptions, benefits, care, and values about physical education programs and sports activities [4-6]. Furthermore, attitudes influence what we do in our lives and the impact of our actions. Thus, those who have a positive attitude toward physical activity probably perform physical activity in their daily lives. With reference to attitudes toward physical activity, studies have indicated that children who have more positive attitudes are more likely to participate in physical activity outside of school [7, 8]. In this respect, Cox et al. [9] have suggested that teachers encourage the transference of physical activity behaviour from within the school to outside the school.

Correspondence address: Ricardo Franco Lima, Polytechnic Institute of Viana do Castelo, School of Sports and Leisure, Complexo Desportivo e Lazer Comendador Rui Solheiro - Monte de Prado, 4960-320, Melgaço, Portugal,

e-mail: ricardo.lima@esdl.ipvc.pt

Received: February 27, 2018

Accepted for publication: July 12, 2018

Citation: Lima RF, Clemente FM, Vale RF. Attitudes toward physical education in Portuguese schools: middle and high school students. Hum Mov. 2018;19(4):64-70; doi: https://doi.org/10.5114/hm.2018.77327. 
It is important to understand the relationship between teachers and students during physical education classes because physical education has the potential to support a healthy lifestyle and an interest for sports and physical activity in children and adolescents [10]. The vast majority of evidence demonstrates that the teacher's teaching approach is responsible for promoting a positive learning environment and involving students in physical activity [5]. On one hand, Woodson-Smith et al. [11] revealed the 'importance of creating positive learning environments at the high school level, developing informed teacher strategies, and understanding students' attitudes toward physical education' (p. 460). On the other hand, physical educators' attitudes regarding students may be negatively influenced by youth body weight and may differ by student gender [12].

According to Subramaniam and Silverman [5], teachers must help students during the exercises involved in different sports during classes and understand that the students in a class will have different levels of physical fitness and different competencies in sports. This is important because studies have revealed that lower perceived athletic competence is associated with low enjoyment of physical education [13]. In this context, physical education teachers need to establish different goals for different students in their lessons because attitudes are influenced by experience, so students tend to participate in physical activities when they perceive the competitive activities to be fun [14, 15]. Furthermore, there is a tendency for positive attitudes to decrease when students get older, and it has been shown that girls' attitudes decrease faster than boys' [3]. Therefore, physical education teachers' behaviour influences the students' tendency to take part in physical activity outside school by helping students to realize the importance of the regular practice of physical activity. Students may even remain committed to these attitudes throughout their lives [16].

Studies have revealed that physical education teachers influence their students' attitudes toward physical education, and the main characteristics teachers should have during lessons are positive attitudes, joy, and happiness [17]. Moreover, despite students' attitudes being related to the teacher's personality, there are other factors that can influence their attitudes - namely, the curriculum, as well as the student's socio-economic status, ethnic group, gender, and age [8]. Research has also shown that students' attitudes toward physical education are more positive among males than in females, and among those who practice sports outside of school than in those who do not; also, attitudes towards physical education tend to become more negative as age increas- es $[5,14,18,19]$. Thus, to increase positive attitudes toward physical education, Fairclough and Stratton [20] studied the contribution of physical education to young people's physical activity levels; they argued that physical education classes may offer a logical and plausible context for regular participation in physical activity because school may provide a background for regular and structured physical activity participation.

In Portugal, there is a lack of research regarding student attitudes toward physical education classes, so the purpose of this study was to reflect and understand the attitudes of Portuguese middle and high school students toward physical education by comparing the variables of gender and activity.

\section{Material and methods}

\section{Participants}

Five public middle and high schools were recruited voluntarily from 3 districts of Portugal (Viana do Castelo, Viseu, and Terceira Island in the Azores). The total of 949 participants ( $48.6 \%$ male, $51.4 \%$ female) aged $13.96 \pm 1.96$ years were involved. Out of these, $50.9 \%$ practised physical activity or sports 2 or 3 times a week at the time of the study. The physical activities or sports performed in the study were aquatic sports (swimming, rowing, canoeing) (9.3\%), combat sports (judo, karate) (11.8\%), and football (10.4\%).

\section{Procedures}

Before the physical education lesson started, study questionnaires were administered by the physical activity teacher or by a responsible teacher who was available. The completion rate was $100 \%$. All students were accustomed to the procedures used in this research.

\section{Instruments}

The instrument applied in the study was the Students' Attitudes Towards Physical Education questionnaire [21]. The questionnaire was translated and modified from the original because the initial version included questions that were irrelevant to this study. The survey was comprised of two sections. The first section requested socio-demographic information (scholar year, age, gender, physical activity practice), and the second section contained 33 items which were to be answered with the use of a scale of 1 to 4 , with 1 meaning 'completely agree' and 4 meaning 'completely disagree'. The items referred to students' 
R.F. Lima, F.M. Clemente, R.F. Vale, Attitudes to physical education in Portuguese schools

physical education class experience (e.g. 'The physical education teacher has the same attitude with all students,' 'The physical education teacher helps me develop my motor skills,' 'The physical education teacher works with the students as a friend') [21]. The protocols for anonymity of the collected data were guaranteed. The questionnaire was validated by a peer review and, for the Portuguese Ministry of Education, through the monitoring register of questionnaires in schools (No. 518600001) and was subject to evaluation by school principals.

\section{Statistical procedures}

A descriptive analysis was performed with percentage, means, and standard deviations. To reduce the 33 items from the survey, an exploratory factor analysis was tested in SPSS 23 software. The exploratory factor analysis is the best statistical method to reduce the numerous variables from questionnaires and create new variables that underlie the previous ones [22].

As indicated in the literature on general attitudes, there are 5 categories derived to analyse attitudes toward physical education [23, 24]. In this study, the exploratory factor analysis resulted in 4 categories that explain $51.28 \%$ of the total variance: F1 (physical education curriculum $[37.015 \%$ from variance; 12 items from the survey]); F2 (physical education teaching [5.994\% from variance; 6 items from the survey]); F3 (practice conditions in physical education $[4.310 \%$ from variance; 4 items from the survey]); and F4 (physical education benefits [3.961\% from variance; 3 items from the survey]). A reliability analysis was assessed by internal consistency. The alpha coefficient (Cronbach's alpha) in different categories resulted in the following values: $\mathrm{F} 1=0.929$ (very high); $\mathrm{F} 2=0.761$ (high); F3 = 0.678 (moderate); F4 $=0.527$ (low) [25].

The MANOVA test analysed the interactions between gender, school year, and participation in sports. In cases involving interactions, a two-way ANOVA was executed for each dependent variable. After that, a one-way ANOVA tested the variance of answers based on the school year. Tukey's honestly significant difference (HSD) test was applied to make a pairwise comparison among school years. An independent $t$-test was carried out to analyse variance between gender and participation in sports. A partial eta squared and an eta squared tested the effect size of the MANOVA, two-way ANOVA, and one-way ANOVA $\left(\eta_{\mathrm{p}}^{2}\right.$ and $\left.\eta^{2}\right)$. Ferguson's classification for $\eta^{2}$ was used as follows [25]: no effect (effect size $[E S]<0.04)$, minimum effect $(0.04 \leqslant E S<0.25)$, moderate effect $(0.25 \leqslant E S<0.64)$, and strong effect
$(\mathrm{ES} \geqslant 0.64)$. Cohen's $d$ was tested after the independent $t$-test to obtain $E S$. The following classification to measure the magnitude of $E S$ was used [25]: no effect $(d<0.41)$, minimum effect $(0.41 \leqslant d<1.15)$, moderate effect $(1.15 \leqslant d<2.70)$, and strong effect $(d$ $\geqslant 2.70$ ). The statistical analysis was carried out with the use of SPSS statistical analysis software (SPSS version 23.0, Chicago, USA). The level of statistical significance was set at $p<0.05$.

\section{Ethical approval}

The research related to human use has been complied with all the relevant national regulations and institutional policies, has followed the tenets of the Declaration of Helsinki, and has been approved by the authors' institutional review board or an equivalent committee.

\section{Informed consent}

Informed parental consent has been obtained for all individuals included in this study. Informed consent was also provided by principals of all participating schools and the Ministry of Education of Portugal.

\section{Results}

The MANOVA tested the variance of the composite of answers among the factors of scholar year, gender, and sports practice. Significant differences in the composite were found for scholar year $\left(p=0.001 ; \eta_{p}^{2}=\right.$ $0.045)$ and sports practice $\left(p=0.018 ; \eta_{p}^{2}=0.015\right)$. No significant differences were found for gender $(p=0.174$; $\left.\eta_{p}^{2}=0.008\right)$. Significant interactions between factors were found in the pairs of scholar year*sports practice $\left(p=0.007 ; \eta_{p}^{2}=0.016\right)$ and school year* ${ }^{*}$ gender*sports practice $\left(p=0.009 ; \eta_{p}^{2}=0.015\right)$. No significant interactions were found in the pairs of scholar year* ${ }^{*}$ ender $\left(p=0.312 ; \eta_{p}^{2}=0.010\right)$ or gender* ${ }^{*}$ sports practice $(p=$ $\left.0.527 ; \eta_{p}^{2}=0.004\right)$.

The two-way ANOVA revealed significant interactions for the pair of school year*sports practice for the variables of physical education teaching ( $p=0.022$; $\left.\eta^{2}=0.021\right)$ and practice conditions in physical education $\left(p=0.007 ; \eta^{2}=0.024\right)$. Significant interactions were also found in school year*sex ${ }^{*}$ sports practice for the variables of physical education teaching ( $p=0.043$; $\left.\eta^{2}=0.018\right)$ and physical education benefits ( $p=0.030$; $\left.\eta^{2}=0.020\right)$.

The independent $t$-test analysed the variance of dependent variables between genders (males, $n=461$; females, $n=488$ ). Males attributed significantly higher meaning (a lower average corresponds to a greater value) 


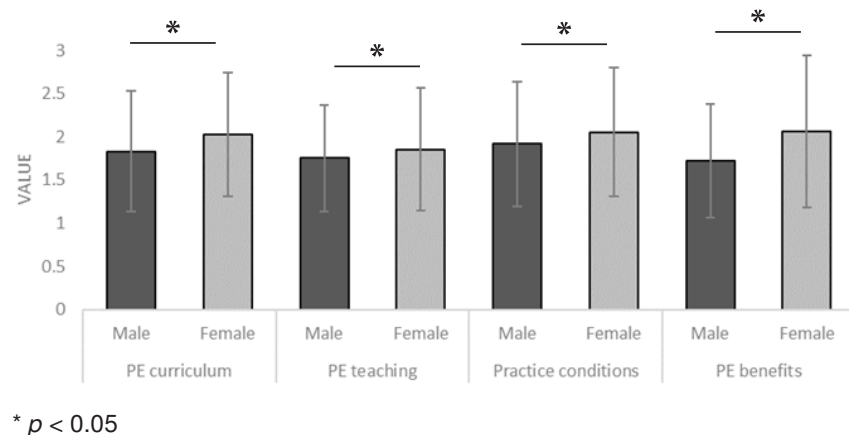

Figure 1. Descriptive statistics (average and standard deviation) of the answers given by male and female physical education (PE) students

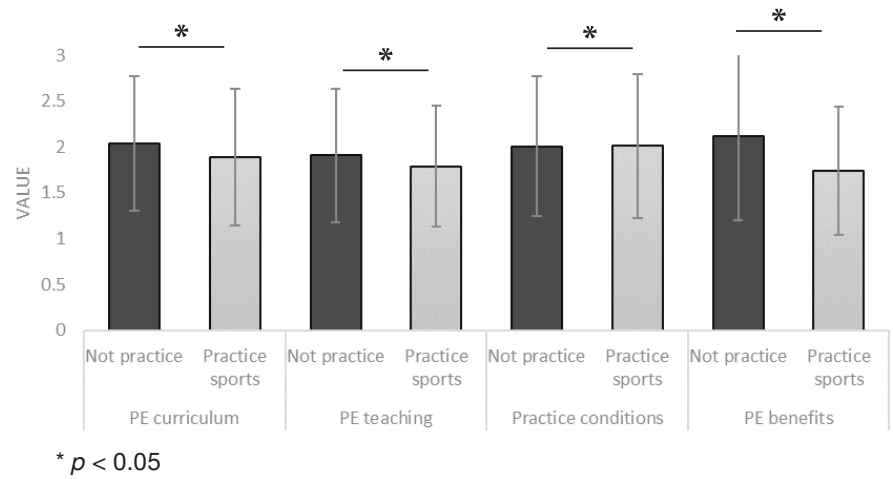

Figure 2. Descriptive statistics (average and standard deviation) of the answers given by physical education (PE) students who practiced sports and those who did not

Table 1. Descriptive statistics (average and standard deviation) of the answers given by students of different school years

\begin{tabular}{lccc}
\cline { 2 - 3 } & $5^{\text {th }}$ to $6^{\text {th }}$ grade $^{\mathrm{a}}$ & $7^{\text {th }}$ to $9^{\text {th }}$ grade $^{\mathrm{b}}$ & $\begin{array}{c}10^{\text {th }} \text { to } 12^{\text {th }} \\
\text { high school grade }^{\mathrm{c}}\end{array}$ \\
\hline PE curriculum & $1.68 \pm 0.77^{\mathrm{b}, \mathrm{c}}$ & $1.87 \pm 0.69^{\mathrm{a}, \mathrm{c}}$ & $2.28 \pm 0.67^{\mathrm{a}, \mathrm{b}}$ \\
PE teaching & $1.71 \pm 0.78^{\mathrm{c}}$ & $1.78 \pm 0.66^{\mathrm{c}}$ & $2.04 \pm 0.62^{\mathrm{a}, \mathrm{b}}$ \\
Practice conditions in PE & $2.02 \pm 0.93$ & $2.00 \pm 0.76$ & $2.01 \pm 0.67$ \\
PE benefits & $1.97 \pm 0.82^{\mathrm{b}}$ & $1.77 \pm 0.75^{\mathrm{a}, \mathrm{c}}$ & $2.07 \pm 0.90^{\mathrm{b}}$ \\
\hline
\end{tabular}

${ }^{\text {a }}$ significantly different from $5^{\text {th }}$ to $6^{\text {th }}$ grade, ${ }^{\text {b }}$ significantly different from $7^{\text {th }}$ to $9^{\text {th }}$ grade,

${ }^{\mathrm{c}}$ significantly different from $10^{\text {th }}$ to $12^{\text {th }}$ high school grade; $p<0.05$

than females to physical education curriculum $(p=$ $0.001 ; d=0.277)$, physical education teaching $(p=$ $0.019 ; d=0.151)$, practice conditions in physical education ( $p=0.004 ; d=0.189)$, and physical education benefits ( $p=0.001 ; d=0.436)$. Descriptive statistics can be found in Figure 1.

Variances between students who practised sports and those who did not were tested with an independent $t$-test. Significantly higher meaning was reported by students who practiced sports for the variables of physical education curriculum ( $p=0.004 ; d=0.205$ ), physical education teaching $(p=0.017 ; d=0.168)$, and physical education benefits ( $p=0.001 ; d=0.466$ ). No significant differences were found between students who practiced sports and those who did not for the variable of practice conditions in physical education ( $p=$ $0.905 ; d=0.008)$. Descriptive statistics are presented in Figure 2.

The one-way ANOVA tested the variance of answers between school years. Significant differences were found between school years for physical education curriculum ( $\left.p=0.001 ; \eta^{2}=0.105\right)$, physical education teaching $\left(p=0.001 ; \eta^{2}=0.040\right)$, and physical education benefits $\left(p=0.001 ; \eta^{2}=0.024\right)$. No significant differences between groups were found for practice conditions in physical education $\left(p=0.980 ; \eta^{2}=\right.$ 0.001). Descriptive statistics can be found in Table 1.
A post-hoc test revealed a higher concordance of $5^{\text {th }}$ to $6^{\text {th }}$ grade students ( $\left.p=0.001\right)$ than the remaining groups for the variable of physical education curriculum. Significantly lower concordance was found in high school students $(p=0.001)$ in comparison with the remaining groups for the physical education teaching variable. Higher concordance was observed in the $7^{\text {th }}$ to $9^{\text {th }}$ grade group in comparison with the remaining groups ( $p=0.026$ for $5^{\text {th }}$ to $6^{\text {th }}$ grade; $p=0.001$ for high school) for the physical education benefits variable. These results suggest that positive attitudes toward physical education decrease as age increases.

\section{Discussion}

The purpose of the study was to reflect on and understand Portuguese middle and high school students' attitudes toward physical education by comparing the gender of the students and the sports activity performed in the class. The results reveal significant differences between groups in terms of school year, gender, and sports practice. Corroborating the outcomes of this study, Lazaverić et al. [26] evaluated attitudes of early-adolescent-aged students toward physical education. The results revealed that male students had more positive attitudes towards physical education than female students. Similarly, in a study that aimed to cover the re- 
R.F. Lima, F.M. Clemente, R.F. Vale, Attitudes to physical education in Portuguese schools

lationship between attitudes and practice of physical activities and sports, Araújo and Dosil [27] found more positive attitudes in male subjects than in female ones. Moreover, a comparison of attitudes toward physical education among Chilean and German schoolchildren showed that boys attributed greater importance to physical education than girls [16]. Conversely, Zeng et al. [6] found that female participants presented more positive attitudes toward their physical education classes than male participants. Differences between genders are related to the content of the class [28]. It can be assumed that the educational contents of physical education are closer to the interests of boys than to those of girls. Thus, it is important to reflect on the curriculum in physical education classes to increase students' motivation and positive attitudes toward physical education.

Besides that, students' leisure-time physical activity is linked to motivation-related experiences in physical education classes [9]. Furthermore, physical education teachers' behaviour is the main reason that adolescents practise physical activity. Barney et al. [29] investigated middle school physical educators' interactions with their students and the effect these interactions had on students' attitudes toward physical education. Results showed that students felt that teachers gave equal treatment to students who were good at physical education and those who were not good at it. Students also reported that teachers gave more help to students who had more difficulties in class, and students appreciated their teacher taking time to ask about their social and affective lives.

Corroborating the current study, other studies have shown that students with more positive attitudes towards physical education are more engaged in physical exercises outside of school [26]. Moreover, there is a positive association between students' attitudes toward sports and their satisfaction with life [30]. Thus, it is crucial to increase physical activity in young people, and physical education teachers have a significant assignment in that regard [9]. Physical education teachers 'must break the negative cycle that exists, not only so that physical education will survive but also that more young people will benefit from teacher programs. By educating them to be physically educated adults, physical education teachers ensure their programs and safe from elimination at times of crisis' (p. 420) [31].

With reference to different grades, the results of the present study suggest that positive attitudes toward physical education decrease as age increases. The same outcomes were obtained in different studies that revealed a decline in attitude scores as students progressed in grade level [5]. Thus, attitudes towards physical ac- tivity and sports are more positive in younger individuals $[6,8,14,16,18,29,32-35]$. With regard to that, Lazarević et al. [26] compared the attitudes of students in the $6^{\text {th }}, 7^{\text {th }}$, and $8^{\text {th }}$ grades towards physical education, and Mercier et al. [2] compared attitudes between the $4^{\text {th }}, 5^{\text {th }}, 6^{\text {th }}, 7^{\text {th }}$, and $8^{\text {th }}$ grades. Results showed a decrease in positive attitudes toward physical education as age increased, especially for girls.

Moreover, Dismore and Bailey [36] analysed students' attitudes within the age ranges of 7-11 and 1214 years, and their results proved significant differences in attitudes during physical education classes between the two age groups. The same authors reported that students improved their attitudes when teachers promoted joy and enjoyment, as this motivated student learning. The learning environment during physical education lessons must be guided constructively and punishment must be avoided. The results of this and other studies can be attributed to the onset of puberty on the part of the students [37] because puberty is one of the factors influencing social life and lifestyle [38].

\section{Conclusion}

The findings of this study revealed significant interactions for the pair of scholar year*sports practice for the variables of physical education teaching and practice conditions in physical education. Significant interactions were also observed for school year*sex* sports practice for the variables of physical education teaching and physical education benefits. Males attributed significantly greater meaning than females to physical education curriculum, physical education teaching, practice conditions in physical education, and physical education benefits. Also, significantly higher meaning was reported by students who practiced sports outside of school for the variables of physical education curriculum, physical education teaching, and physical education benefits. No significant differences were found between participants who practiced sports and those who did not for the variable of practice conditions in physical education. Finally, significant differences were observed between participants in different school years for the variables of physical education curriculum, physical education teaching, and physical education benefits. No significant differences between school year groups were noted for the variable of practice conditions in physical education.

In summary, age and gender can be important factors for understanding students' attitudes toward physical education. Therefore, in physical education lessons, the teacher needs to motivate the class and consider 
the variables that can influence student physical activity behaviour and lifestyle.

\section{Disclosure statement}

No author has any financial interest or received any financial benefit from this research.

\section{Conflict of interest}

The authors state no conflict of interest.

\section{References}

1. Albarracin D, Sunderrajan A, Lohmann S, Chan S, Jiang D. The psychology of attitudes, motivation, and persuasion. In: Albarracin D, Johnson BT (eds.), The handbook of attitudes. New York: Routledge; 2018; 1-5.

2. Mercier K, Donovan C, Gibbone A, Rozga K. Three-year study of students' attitudes toward physical education: grades 4-8. Res Q Exerc Sport. 2017;88(3):307-315; doi: 10.1080/02701367.2017.1339862.

3. Silverman S. Attitude research in physical education: a review. J Teach Phys Educ. 2017;36(3):303-312; doi: 10.1123/jtpe.2017-0085.

4. Ward P, Parker M, Sutherland S, Sinclair C. A critical examination of the curriculum of physical education teacher education doctoral programs. J Teach Phys Educ. 2011;30(2):145-156; doi: 10.1123/jtpe.30.2.145.

5. Subramaniam PR, Silverman S. Middle school students' attitudes toward physical education. Teach Teach Educ. 2007;23(5):602-611; doi: 10.1016/j.tate.2007.02.003.

6. Zeng HZ, Hipscher M, Leung RM. Attitudes of high school students toward physical education and their sport activity preferences. J Soc Sci. 2011;7:529-537; doi: 10.3844/jssp.2011.529.537.

7. Phillips SR, Silverman S. Upper elementary school student attitudes toward physical education. J Teach Phys Educ. 2015;34(3):461-473; doi: 10.1123/jtpe.20140022.

8. Agbuga B, Xiang P, McBride R. Students' attitudes toward an after-school physical activity programme. Eur Phys Educ Rev. 2013;19(1):91-109; doi: 10.1177/1356 336X12465511.

9. Cox A, Smith A, Williams L. Change in physical education motivation and physical activity behavior during middle school. J Adolesc Health. 2008;43(5):506513; doi: 10.1016/j.jadohealth.2008.04.020.

10. Colquitt G, Walker A, Langdon JL, McCollum S, Pomazal M. Exploring student attitudes toward physical education and implications for policy. Sport SPA. 2012; $9(2): 5-12$.

11. Woodson-Smith A, Dorwart CE, Linder A. Attitudes toward physical education of female high school students. Phys Educ. 2015;72(3):460-479.

12. Peterson JL, Puhl RM, Luedicke J. An experimental assessment of physical educators' expectations and attitudes: the importance of student weight and gender.
J Sch Health. 2012;82(9):432-440; doi: 10.1111/j.17461561.2012.00719.x.

13. Cairney J, Kwan MY, Velduizen S, Hay J, Bray SR, Faught BE. Gender, perceived competence and the enjoyment of physical education in children: a longitudinal examination. Int J Behav Nutr Phys Act. 2012; 9:26; doi: 10.1186/1479-5868-9-26.

14. Silverman S, Subramaniam PR. Student attitude toward physical education and physical activity: a review of measurement issues and outcomes. J Teach Phys Educ. 1999;19(1):97-125; doi: 10.1123/jtpe.19.1.97.

15. Bernstein E, Phillips SR, Silverman S. Attitudes and perceptions of middle school students toward competitive activities in physical education. J Teach Phys Educ. 2011;30(1):69-83; doi: 10.1123/jtpe.30.1.69.

16. Carcamo-Oyarzun J, Wydra G, Hernandez-Mosqueira C, Martinez-Salazar C. Attitudes towards physical education: degrees of importance and conformance among schoolchildren in Chile and Germany. An intercultural comparison [in Spanish]. Retos. 2017;32: 158-162.

17. Carlson TB. We hate gym: student alienation from physical education. J Teach Phys Educ. 1995;14(4):467-477; doi: $10.1123 /$ jtpe.14.4.467.

18. Araújo AT, Dosil J. The influence of attitudes toward physical activity and sports. Motriz: Rev Educ Fis. 2015; 21(4):344-351;doi:10.1590/S1980-65742015000400002.

19. Donovan CB, Mercier K, Phillips SR. Investigating attitudes toward physical education: validation across two instruments. Meas Phys Educ Exerc Sci. 2015;19(2): 91-98; doi: 10.1080/1091367X.2015.1012511.

20. Fairclough S, Stratton G. 'Physical education makes you fit and healthy'. Physical education's contribution to young people's physical activity levels. Health Educ Res. 2005;20(1):14-23; doi: 10.1093/her/cyg101.

21. Al-Liheibi AHN. Middle and high school students' attitudes toward physical education in Saudi Arabia. Fayetteville: University of Arkansas; 2008.

22. Pestana MH, Gageiro JN. Data analysis for social sciences: the complementarity of SPSS [in Portuguese]. Lisboa: Sílabo; 2014.

23. Li F, Chen J, Baker M. University students' attitudes toward physical education teaching. J Teach Phys Educ. 2014;33(2):186-212; doi: 10.1123/jtpe.2012-0187.

24. Figley GE. Determinants of attitudes toward physical education. J Teach Phys Educ. 1985;4(4):229-240; doi: 10.1123/jtpe.4.4.229.

25. Ferguson CJ. An effect size primer: a guide for clinicians and researchers. Prof Psychol Res Pract. 2009; 40(5):532-538; doi: 10.1037/a0015808.

26. Lazarević D, Orlić A, Lazarević B, Janić S. Attitudes of early adolescent age students towards physical education. Phys Cult. 2015;69(2):88-98; doi: 10.5937/fizkul1502088L.

27. Araújo AT, Dosil J. Relations between attitudes and practice of physical activity and sport in men and women [in Spanish]. Cuad Psicol del Deport. 2016;16(3):67-72. 


\section{HUMAN MOVEMENT}

R.F. Lima, F.M. Clemente, R.F. Vale, Attitudes to physical education in Portuguese schools

28. Luke MD, Sinclair GD. Gender differences in adolescents' attitudes toward school physical education. J Teach Phys Educ. 1991;11(1):31-46; doi: 10.1123/jtpe.11.1.31.

29. Barney D, McGaha P, Christenson P. Does the middle school physical educator make a difference in students' attitudes toward physical education? Mo J Health Phys Educ Recr Dance. 2013;23:66-76.

30. Swanepoel E, Surujal J, Dhurup M. Attitude towards sport and physical activity, self-esteem, life satisfaction relationships and variations in terms of gender: perspectives from university students. Afr J Phys Health Educ Recr Dance. 2015;Suppl. 1:14-28.

31. Tannehill D, Romar J-E, O’Sullivan M, England K, Rosenberg D. Attitudes toward physical education: their impact on how physical education teachers make sense of their work. J Teach Phys Educ. 1994;13(4):406-420; doi: $10.1123 /$ jtpe.13.4.406.

32. Cea Morales S, Véliz C, Aravena Garrido C, Maureira Cid F. Perception of the students of physical education of the UISEK of Chile towards their teachers [in Spanish]. Cuad Psicol del Deporte. 2014;14(1):23-28.

33. Čepelionienè J, Ivaškienè V. The shift of students attitudes towards the teacher of physical education. Educ Phys Train Sport. 2014;94(3):10-15.

34. Ceyhun BM, Sezgin S, Alperen E, Kerim YA, Samet AF, Ali A, et al. An assessment of the attitude of the students of sport management department towards the departments of physical education and sport teaching and coaching training. Sci Mov Health. 2013;13(Suppl.):403-408.

35. Russ LB, Webster CA, Beets MW, Phillips DS. Systematic review and meta-analysis of multi-component interventions through schools to increase physical activity. J Phys Act Health. 2015;12(10):1436-1446; doi: 10.1123/ jpah.2014-0244.

36. Dismore H, Bailey R. 'It's been a bit of a rocky start': attitudes toward physical education following transition. Phys Educ Sport Pedag. 2010;15(2):175-191; doi: 10.1080/17408980902813935.

37. Esteban-Cornejo I, Tejero-González CM, MartinezGomez D, Cabanas-Sánchez V, Fernández-Santos JR, Conde-Caveda J, et al. Objectively measured physical activity has a negative but weak association with academic performance in children and adolescents. Acta Paediatr. 2014;103(11):501-506; doi: 10.1111/apa.12757.

38. Ballinger D. Physical activity behavior and motivation. In: Ayers SF, Saricsany MJ (eds.), Physical education for lifelong fitness: the physical best teacher's guide. Champaign: Human Kinetics; 2011; 13-36. 